\title{
STUDIES ON HABIT AND HABITAT, EXTERNAL MORPHOLOGY, FEEDING CAPACITY AND PREY PREFERENCE OF GARDEN JUMPING SPIDER, Opisthoncus SPECIES
}

\author{
S.N. CHAUBEY ${ }^{1}$ \\ Department of Zoology, S.D.J.P.G. College Chandeshwar, Azamgarh, U.P., India
}

\begin{abstract}
Laboratory experiments were carried out to investigate habit and habitat, external morphology, preying capacity and prey preference of garden jumping spider, Opishoncus species collected from different places of U.P. India. It is found on trees, shrubs and paddy plants. Like other jumping spiders of family salticidae, these spiders do not build webs also and are sophisticated and active hunters. These have ability to capture prey several times their size. These have two very large eyes on the front of their face, another two smaller ones around the sides and four on top, giving them excellent vision in most directions and an ability to interact with human observers. The spiders are brown in colour with white pattern on its abdomen and thorax. Patterns may vary between individuals.
\end{abstract}

KEYWORDS: Opisthoncus, Araneae, Salticidae, Habit and Habitat, Morphology, Preying Capacity, Prey Preference, BioControl Agent

Spiders are of major importance in ecosystems and are recognized as effective natural control agents in agroecology. These are carnivorous arthropods and are found all over the world in almost every kind of habitat. They mainly prey on insects, although they may also feed on various other kinds of prey. The population densities and species abundance of spider communities in agricultural fields can be as high as in natural ecosystems (Tanaka, 1989).

Salticidae is a very large family contains the most colourful species of spiders. They are easily recognized by their eyes pattern. They have very good eyesight and very active. Each species in this family have different colourful patterns on their bodies. Jumping spiders are generally recognized by their eye pattern. All jumping spiders have four pairs of eyes with very large anterior median eyes. These are generally diurnal active hunters. Their well developed internal hydraulic system extends their limbs by altering the pressure of body fluid (haemolymph) within them. This enables the spiders to jump without having large muscular legs like a grasshopper. Most jumping spiders can jump several times the length of their body. When a jumping spider is moving from place to place, and especially just before it jumps, it tethers a filament of silk (or dragline) to whatever it is standing on. Should it fall for one reason or another, it climbs back up the silk tether.

Jumping spiders are active hunters which means they do not rely on a web to catch their prey. Instead, these spiders stalk their prey. They use their superior eyesight to distinguish and track their intended meals, often for several inches. Then they pounce, giving the insect little to no time to react before succumbing to the spider's venom.

Gajbe (2004) has provided a detailed account of spiders of Jabalpur, Madhya Pradesh, Rao et al. (2005) have described arachnid fauna of Nallamalai region, Eastern Ghats Andhra Pradesh (India) and Majumder (2007) has given a detailed account of taxonomic studies of some spiders from Mangrove and Semi-Mangrove areas of Sunderban, studies on some spiders from Eastern Coastal region of India and various aspects of spiders of Sunderbans, West Bengal (India) respectively. Recently Chaubey and Mishra (2017) have reported Eucta chamberlini (Simon), Chaubey (2017) has given descriptive account of Argiope aemula and Chaubey and Yadav (2017) have reported Plexippus paykuli (Audeuin) from U.P. India. They have described habit and habitat, morphology, feeding capacity and prey preference of these spider species and also suggested for use of spiders as bio-control agents in controlling insect pests of crop fields.

From the review of literature, it appears that role of spiders as bio-control agents in agriculture, poultry as well as in controlling house-hold insects is being studied in various parts of the world, but unfortunately, no proper investigation, regarding role of these efficient bio-control agents in India is scanty.

In the present investigation, therefore, it has been to find out habit and habitat, external morphology, preying capacity and prey preference of garden jumping spider

${ }^{1}$ Corresponding author 
Opisthoncus species collected from various places of U.P. (India).

\section{MATERIALS AND METHODS}

\section{Collection of Spiders}

Individuals of Opisthoncus species were collected from walls, crop fields, orchards, ornamental and wild plants.

\section{Methods of Collection}

Following techniques were used for collection of spiders:

\section{Jarring}

The foliage spider fauna was collected by jerking the plants on a cloth sheet from which the specimens were transferred alive in to plastic containers having pores in their corks for aeration and brought to the laboratory for studies.

\section{Direct Hand Picking}

Collection of most web building spiders was made by direct hand picking with the help of test tubes.

\section{Inverted Umbrella}

In this method an inverted umbrella was placed below flowering shoots and bushes and when the tree or branch was thoroughly shaken, spiders along with insects fallen to the inverted umbrella. After removing leaves, spiders were transferred into collecting tubes.

\section{Preservation}

Before the spiders were permanently preserved they were arranged properly. For this, collected specimens were transferred into petridish containing Isopropyl alcohol. It was kept covered undisturbed for about 2 or 3 hours in order to allow the relaxation of body muscles. The body parts like legs, abdomen, and palps were then arranged in a life like manner with the help of forceps and brush. Spiders were then kept in alcohol in a closed pair of petridish overnight before transferring to tubes for permanent preservation. The glass vial containing preserved specimens were stoppered by a rubber cork to prevent evaporation of alcohol. Alternatively, glass vials were plugged by cotton and group of these tubes were then placed in large bottle containing alcohol. This was the method used for preserving most specimens. Each collecting tube enclosed a label indicating the collection data. Collection data includes the name of the collector, place of collection, date of collection and habitat of collection.

\section{Photography}

Live photographs of all important spiders were taken with the help of Web Cam of 12 mega pixel attached to computer. For taking alive photographs, the spiders were anesthetized with mild doses of chloroform in specimen tubes. Generally, major diagnostic features such as dorsal view, ventral view, ocular area and side view were taken for the study. Natural photographs of spiders were taken while they were feeding on insects.

\section{Identification}

It was done on the basis of morphometric characters of various body parts. The help was mainly taken from the keys and catalogues provided by Biswas and Biswas (2003) and Plantik (2004), information and photographs available on internet and other relevant literature.

\section{Study of Prey Choice}

To study the prey choice of the collected spiders, adult house flies, rice moth, mosquitoes and their larvae and small insects were supplied to spiders which were kept under rearing chambers.

Each rearing chamber $(9.5 \mathrm{~cm}$ height, $6.0 \mathrm{~cm}$ length and width) was consisted of transparent plastic containers. The lid of each container was provided with small holes for aeration. Since, spiders are highly cannibalistic, individual spiders were kept in separate chambers

To study prey choice, spiders were kept starved for $24 \mathrm{~h}$, then each spider was supplied with larvae and adults of moths, house flies and mosquitoes along with small insects collected from houses and surroundings (five individuals of each kind of prey in each rearing chamber). After $12 \mathrm{~h}$ number of fed and live prey individuals were counted to find out preference of their prey. Attempts were also made to take live photographs while spiders were preying. 


\section{Study of Preying Potential}

For this purpose spiders were kept starved for $24 \mathrm{~h}$ and then each spider was supplied with various kinds of insect pests like adult moths, house flies and mosquitoes (ten individuals of each type) separately in their individual rearing chambers. After $12 \mathrm{~h}$, dead, fed and live prey were counted.

\section{Statistical Analyses}

Each experiment was repeated ten times and student's t-test was applied for comparison between two sample means.

\section{RESULTS}

\section{Classification}

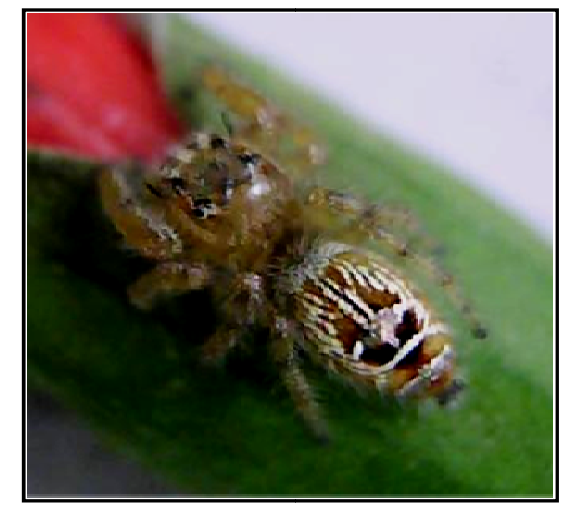

Figure 1
Phylum: Arthropoda, Class: Arachnida, Order:Araneae, Family: Salticideae, Genus: Opisthoncus

\section{Habit and Habitat}

These spiders do not build webs and are sophisticated and active hunters, often capturing prey several times their size.

\section{Description}

Body length $10 \mathrm{~mm}$. The spider is brown in colour with white pattern on its abdomen and thorax. Patterns may vary between individuals. These have two very large eyes on the front of their face, another two smaller ones around the sides and four on top, giving them excellent vision in most directions and an ability to interact with human observers. (Figure 1 and 2).

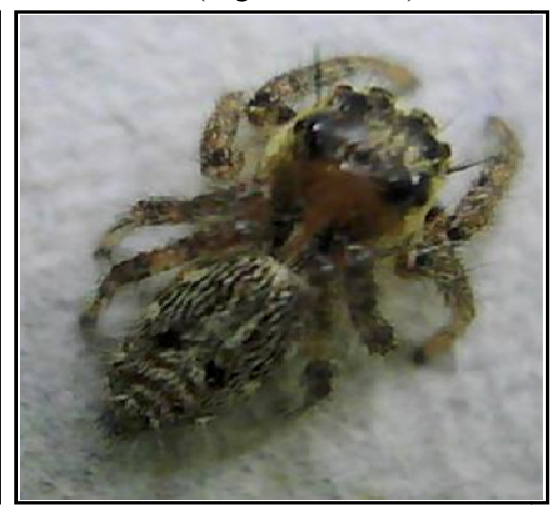

Figure 2

Figure 1 and 2: Dorsal Views of Opisthoncus Spiders Collected During Present Investigation, Opisthoncus Species Hunting/Economic Importance

The garden jumping spider hunts by jumping onto its prey, usually from a higher leaf to a lower leaf. The spider can even capture a flying target. Jumping Spider can

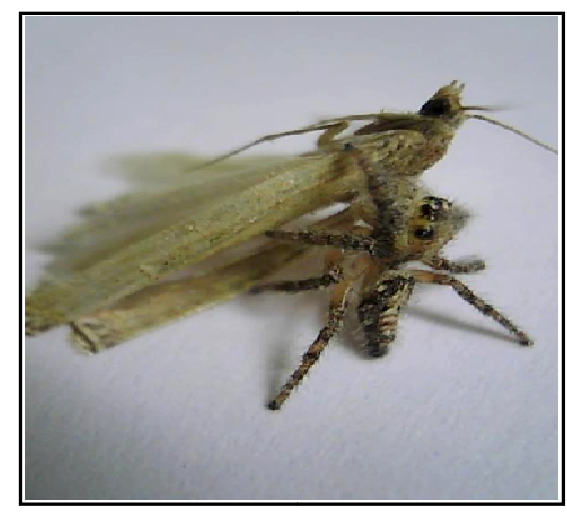

Figure 3: Feeding on Moth easily walk on the bottom side of a waxy leaf without any problem. These feed actively on adults of moth (Figure 3) as well as mosquitoes (Figure 4). Thus it can also be used as bio-control agent for controlling insect pests including lepidopteran pests and mosquitoes (Table 1).

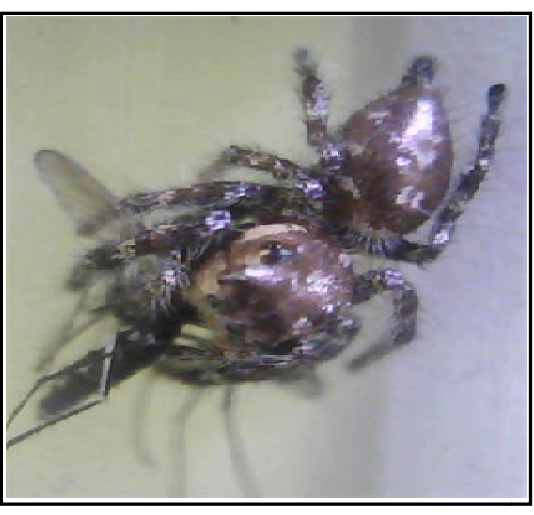

Figure 4: Feeding on Mosquito 
CHAUBEY: STUDIES ON HABIT AND HABITAT, EXTERNAL MORPHOLOGY, FEEDING CAPACITY AND PREY...

Table 1: Feeding potential/ prey preference of Opisthoncus spider species

\begin{tabular}{|c|c|c|c|c|c|}
\hline \multicolumn{6}{|c|}{ Type/Number of prey consumed/24h / Spider (Mean \pm S.D.) } \\
\hline Sr. No. & Lepidoptera & Diptera & Homoptera & Orthoptera & Total \\
\hline 1 & 6 & 5 & 3 & 2 & 16 \\
\hline 2 & 5 & 5 & 2 & 2 & 14 \\
\hline 3 & 5 & 4 & 2 & 3 & 14 \\
\hline 4 & 6 & 5 & 2 & 3 & 16 \\
\hline 5 & 4 & 5 & 3 & 3 & 15 \\
\hline 6 & 5 & 4 & 2 & 2 & 13 \\
\hline 7 & 6 & 5 & 2 & 3 & 16 \\
\hline 8 & 6 & 4 & 3 & 2 & 15 \\
\hline 9 & 5 & 4 & 2 & 2 & 13 \\
\hline 10 & 5 & 5 & 2 & 3 & 15 \\
\hline Mean \pm S.D. & $5.30 \pm 0.64$ & $4.60 \pm 0.49^{b}$ & $2.30 \pm 0.46^{\mathrm{a}}$ & $2.50 \pm 0.50^{*}$ & $14.70 \pm 1.10^{\mathrm{a}}$ \\
\hline
\end{tabular}

Significance level ${ }^{\mathrm{a}} 0.001,{ }^{\mathrm{b}} 0.05$ and ${ }^{*}$ not significant when compared with adjacent means

\section{DISCUSSION}

Individuals of Opisthoncus species are usually found hunting on board green leaves during the days. This spider species is being reported here for the first time from U.P. (India). Its identification was based only on morphological similarities between photographs available on Internet (Figure 1 and 2). It was collected from shrubs, trees and paddy crop fields. It fed actively on moths as well as mosquitoes. Similar observation has also been reported by Mishra (2012). It can also be used as bio-control agent for controlling lepidopteran pests and mosquitoes as generalist predators which can be used as effective biocontrol agents as mentioned by Symondson et al., (2002).

\section{ACKNOWLEDGEMENT}

Author is thankful to Dr. Shanker Talukder and Dr. Thirumali, Scientist-F, Zoological Survey of India, Kolkata for providing necessary literature, to Dr. D.P. Dwivedi former Principal for valuable suggestions. C.S.I.R. New Delhi is deeply acknowledged for providing BOD incubator during work on research project No. 37/1332/08/EMRII sanctioned to author.

\section{REFERENCES}

Biswas B.K. and Biswas K., 2003. Fauna of Sikkim (Araneae: Spiders), State fauna Series, 3: 357-500.

Chaubey S.N. and Mishra R.S., 2016. Habit and habitat, morphology, feeding capacity and prey preference of six humped dome spider, Cyrtophora cicatrosa Stoliczka. Journal of Applied Bioscience, 42(2): 109-113.
Chaubey S.N. and Mishra R.S., 2017 ${ }^{\text {a }}$ Studies on the habit and habitat, morphology, feeding capacity and prey preference of six humped dome spider Cyrtophora citricola Simon. Indian Journal of Scientific Research, 7(2): 39-45.

Chaubey S.N., 2017. Studies on habit and habitat, external morphology, feeding capacity and prey preference of true worb-weaving spider, Argiope aemula (Walekenaer). Indian Journal of Scientific Research, 15(1): 30-34.

Chaubey S.N. and Mishra R.S., 2017. Study on the morphology, feeding capacity and prey preference of long jawed spider, Eucta chamberlini (simon). Journal of Experimental Zoology India, 20(1): 6165.

Chaubey S.N. and Yadav P.R., 2017. Studies on habit and habitat, external morphology, feeding capacity and prey preference of zebra jumper spider Plexippus paykuli (Audeuin) Journal of Experimental Zoology India, 20(2): 901-905.

Gajbe P., 2004. Spiders of Jabalpur, Madhya Pradesh (Arachnida: Araneae). Zoological Survey of India, Kolkata. pp. 1-154.

Im M.S. and Kim S.T., 1999. Studies on the ecological characteristics of the spiders as natural enemy for rice insect pest at rice paddy field in Koesan area, Chungcheongbuk-do. Journal of Development of Agricultural Resources. Kontuk Univ., 21: 57-66. 


\section{CHAUBEY: STUDIES ON HABIT AND HABITAT, EXTERNAL MORPHOLOGY, FEEDING CAPACITY AND PREY...}

Kim J.P. and Kim J.C., 1995. Influence of the levee and paddy burning on the fauna of over wintering spider. Kor. Arachnol., 11(2): 59-71.

Majumder S.C., 2004. Description of a new species of Wolf spider (Araneae: Lycosidae) from crop fields of Sunderban estuary, West Bengal: J. Bombay Nat. Hist. Soc., 101(1): 121-123.

Majumder S.C., 2005. Studies of some spiders from eastern coastal region of India. Men. Zool. Surv. India, 20(3): 1-57.

Majumder S.C., 2007. Pictorial Handbook on Spiders of Sunderbans West Bengal: 1-137. (Published by the Director, Zool. Surv. India, Kolkata).

Mishra R.S., 2012. Unpublished Ph.D. Thesis entitled "Studies on the role of predatory insects in biological control of rice pests of middle east (U.P.)" V.B.S. Purvanchal University Jaunpur.

Mishra RS., Ahmad G. and Chaubey S.N., 2012 ${ }^{\mathrm{a}}$. Study on the morphology, feeding capacity and prey preference of Neoscona crucifera and $N$. adianta (Orb-weaving spiders). Indian J. L. Sci., 1(2): 2934.

Mishra R.S., Ahmad G. and Chaubey S.N., 2012 ${ }^{\mathrm{b}}$. Study on the morphology, feeding capacity and prey preferences of Orb-weaving spider, Neoscona nautica. J. Exp. Zool. India, 15(2): 467-472.

Nentwig W., Hänggi A., Kropf C. and Blick T., 2003. Central European Spiders determination key. www.araneae.unibe.ch (assessed 8.12.2003).

Platnick N.I., 2007. The world spider catalog, version 8.0. American Museum of Natural History. Online at http:// research.amnh.org/entom ology/spiders/catalog/index.html.
Rao T.K., Bastawade D.B., Maqsood Javed S.M. and Siva Rama Krishna I., 2005. Arachnid fauna of Nallamalai Region, Eastern Ghats, Andhra Pradesh, India, Rec. Zool. Surv. India, Occ. Paper No. 239: 1-42. (Published by the Director, Zool Surv. India, Kolkata).

Song Y.H. and Lee Y.G., 1994. Studies on the spider fauna in the paddy fields of Chinju and Namhae areas. Korean Jour. Environ. Agric., 13(1): 98-110.

Symondson W.O.C., Sunderland K.D. and Greenstone M.H., 2002. Can generalist predators be effective biocontrol agents? Annual Review of Entomology, 47: 561-594.

Tanaka K., 1989. Movement of spiders in arable land. Plant Protection, 43(1): 34-39.

Vijayalakshmi K. and Ahimaz P., 1993. Spiders: An Introduction. Published by: Cre-A: 268 Royapettah High Road Madras 600014. Printed: at Sudersan Graphics Madras 600017 pp. 1-112.

Yadav A., Chaubey S.N. and Beg M.A., 2012 . Morphology, prey preference and feeding capacity of Decorative spider, Leucauge decorata (Blackwall) from Azamgarh, India. Journal of Applied Bioscience, 38(1): 63-67.

Yadav A., Chaubey S.N. and Beg M.A., 2012 ${ }^{\mathrm{b}}$. Hippasa holmerae (Thorell) as biocontrol agent for insect pests of crop fields collected from Azamgarh and Mau districts of U.P. India. Journal of Experimental Zoology India, 15(2): 495-498.

Yamano T., 1977. Seasonal fluctuation of population density of spiders in paddy field in Kyoto city. Acta Arachnol. 27 (Special Number): 253-260. 